\title{
Smoking, hypertension, and colonic anastomotic healing; a combined clinical and histopathological study
}

\author{
A Fawcett, M Shembekar, J S Church, R Vashisht, R G Springall, D M Nott
}

\begin{abstract}
Background-Large bowel anastomotic breakdown occurs as a result of perianastomotic ischaemia. Preservation of the macroscopic arterial supply to the perianastomotic tissues is vital, but little is known about the influence of microvascular disease on anastomotic healing.

Aims-To study the associations between risk factors for macrovascular disease, the presence of colonic microvascular disease, and the incidence of anastomotic dehiscence.
\end{abstract}

Patients-147 consecutive colonic surgery patients.

Methods-The prevalence of smoking, hypertension, diabetes, and ischaemic heart disease were established retrospectively from patient notes. These risk factors were correlated with histopathological assessment of resection margin vasculature and clinical follow up.

Results-Smoking and hypertension were significantly associated with an increased incidence of anastomotic dehiscence and microvascular disease. Microvascular disease was positively correlated with an increased incidence of anastomotic dehiscence.

Conclusions-Microvascular disease predisposes to anastomotic breakdown. This effect may in part be due to vasospasm in the diseased vessels, which are hypersensitive to serotonin, a vasoactive amine known to be present in increased quantities

- in the serum of smokers, hypertensives, and after surgery. Treatment with serotonin antagonists in the perioperative period may be beneficial to anastomotic healing, helping to maintain microvascular flow.

(Gut 1996; 38: 714-718)

Department of

Surgery

A Fawcett

J S Church

R Vashisht

R G Springall

D M Nott

and Histopathology M Shembekar

Charing Cross

Hospital, London

Correspondence to: Mr A Fawcett, Department of Surgery, Charing Cross of Surgery, Charing Cross Road, Hammersmith
London W6 8RF.

London W6 8RF. 20 November 1995
Keywords: anastomosis, atherosclerosis, colon, dehiscence, smoking, hypertension.

Clinically apparent large bowel anastomotic breakdown is associated with a significant morbidity and mortality and has been shown to occur in up to 30 per cent of large bowel anastomoses after resection for adenocarcinoma. ${ }^{1}$ Predisposing factors may be related to poor surgical technique or sepsis but the final common pathway seems to be reduced tissue nutrition secondary to ischaemia. ${ }^{1-8}$ Great care is taken to preserve the macroscopic arterial supply to the cut ends of the bowel at operation. Comparatively little attention has focused on the state of the microvasculature of the large bowel and the possible consequences of intimal disease in the vessels of the bowel wall, and whether the same risk factors that predispose to peripheral arterial disease may also be associated with colonic microvascular disease.

Atherosclerotic disease in the large visceral arteries is comparatively common. Derrick et al found evidence of disease in 44 per cent of the coeliac arteries and 37 per cent of the superior mesenteric arteries in a series of 74 necropsy specimens. ${ }^{9}$ Such disease contributes little in terms of morbidity and mortality, however, when compared with similar disease in the coronary and cerebral circulations, principally because of the effectiveness of the collateral circulation established in the colonic wall and mesentery. But disease found more distally in the circulation, about which there are few published data, may have a significant effect on blood flow in the wall of the bowel, particularly after surgical procedures in which the collateral channels may be interrupted.

Serotonin is a vasoactive amine derived from tryptophan and stored in the bowel mucosa and circulating platelets. In physiological doses, and in the presence of an intact, functional endothelium, serotonin causes relaxation of vascular smooth muscle. ${ }^{10}$ This effect is brought about by stimulation of a specific (S1) receptor on the endothelial cell membrane, which leads to the release of an endothelium derived relaxing factor (EDRF), now known to be nitric oxide, which diffuses into the underlying smooth muscle and stimulates relaxation. In the presence of a diseased endothelium, however, vasoconstriction occurs in response to serotonin. This is thought to occur because the diseased endothelium no longer acts as a diffusion barrier to the serotonin, which can thus pass across the endothelium to directly stimulate a second class of serotonin receptor (S2) on the membrane of the smooth muscle cells, leading to vasoconstriction. Furthermore, it seems the damaged endothelium no longer releases EDRF, which may have served to partially counteract this smooth muscle contraction. ${ }^{10}$ Plasma concentrations of serotonin are known to be increased in smokers, ${ }^{11}$ people with hypertension, ${ }^{12}$ and during routine abdominal surgery, as a result of the classic stress response combined with increased platelet degranulation after trauma. ${ }^{13}$ Serotonin has also been implicated in other postoperative complications (for example, adult respiratory distress syndrome) 
TABLE I Pro forma for recording patient details

\begin{tabular}{l} 
Patient name \\
Date of birth \\
Sex \\
Hospital number \\
History of smoking? \\
Current smoker \\
Ex-smoker \\
Non-smoker \\
History of hypertension? \\
History of diabetes? \\
IDDM \\
NIDDM \\
History of ischaemic heart disease? \\
Previous MI \\
Angina \\
Date of surgery \\
Nature of operation \\
Grade of principal surgeon \\
Use of proximal diversion \\
Pathology necessitating surgery \\
Evidence of anastomotic leakage \\
Clinical (confirmed at laparotomy) \\
Radiological \\
\hline
\end{tabular}

involving hypoperfusion. ${ }^{13}$ In vivo animal studies have shown that atherosclerosis renders the mesenteric circulation of primates exquisitely sensitive to the vasospastic effects of serotonin, virtually abolishing blood flow to the colon, ${ }^{14}$ and a pronounced sensitivity to serotonin has recently been shown in human mesenteric arteries in vitro. ${ }^{15}$ Therefore microvascular disease in the colon, and the hypersensitivity to serotonin seen in the presence of such disease may have a significant role in the aetiology of anastomotic dehiscence, by reducing local perfusion. If so, perioperative administration of a serotonin antagonist may improve colonic perfusion and reduce the incidence of this potentially fatal complication.

The aims of this study were therefore to investigate the possible associations between; (a) risk factors for macrovascular disease and the presence of microvascular disease in the colon, and (b) the presence of microvascular disease and the incidence of anastomotic breakdown.

\section{Methods}

Patients

A retrospective study of left sided colorectal surgery at Charing Cross Hospital between January 1991 and December 1993 was carried out. A total of 147 consecutive patients who had undergone left sided colonic resection and anastomosis were studied, including both emergency and elective cases. The range of operations included anterior resection, sigmoid colectomy, left sided hemicolectomy, reversal of Hartmanns procedure, and one closure of colostomy, in which a further resection was undertaken before the formation of the anastomosis.

\section{Retrospective survey}

The notes of all patients who had undergone these procedures were carefully studied, and their demographic details recorded on a pro forma (Table I).

Patients smoking at the time of admission and those who had smoked for in excess of 25 years before giving up were classed as smokers. The hypertensive and diabetics in the study were those patients receiving active treatment for their condition. Histories of ischaemic heart disease were validated as far as possible by inspection of electrocardiographic changes and recorded cardiac enzyme changes.

If a leak was suspected on clinical grounds and then confirmed radiologically, it was classed as a clinical leak. Only those leaks identified by a contrast study performed as a routine postoperative check and in the absence of clinical signs of leakage were classed as radiological leaks.

\section{Histopathological assessment}

The resection specimens of each patient identified in this study were then subjected to a blinded, histological assessment of small vessel disease in the colonic wall, by an experienced pathologist. Colonic resection specimens were formalin fixed and paraffin wax processed with routine sections being taken for haematoxylin and eosin staining. A minimum of two sections of the anastomotic margins were examined under light microscopy. Vessels were examined in the all layers of the bowel wall. Pathological changes recorded included primary pathology and vessel wall changes of atherosclerotic disease, namely intimal hyperplasia, tunica media degeneration, and atherosclerotic plaque formation, including percentage luminal occlusion $(<25,25-50,>50$ per cent).

The presence of small vessel disease was correlated with the expression of macrovascular (MAVD) risk factors by each patient. The incidence of small vessel disease in those patients who developed anastomotic dehiscence was compared with that seen in the remaining patients whose anastomoses healed uneventfully.

\section{Statistical analysis}

Simple $\chi^{2}$ analysis was used to test the correlations between the presence of macrovascular disease risk factors, the existence of microvascular disease, and the incidence of anastomotic dehiscence. The same analysis was used when comparing the results of the anastomotic leak group to the remainder of the study patients.

\section{Results}

\section{Operation details (Table II)}

The notes of 147 patients were reviewed. Altogether, 12 anastomotic leaks were identified. Six of these were clinical leaks, which were later confirmed at a second laparotomy, and the remaining six were radiological and required no further surgical intervention. Of 80 men studied, eight $(10 \%)$ were found to have developed a leak, compared with four of 67 women $(6 \%)$. The mean age of the dehisced group was $66 \cdot 1$ years, compared with $67 \cdot 3$ years in the intact group. Five leaks occurred in the presence of a proximal diversion.

Of the 60 anterior resections, stapling devices were used to close 53 of the anastomoses, with the remaining seven being hand 
TABLE II Range of surgical procedures reviewed; incidence of radiological and clinical leakage, and age/sex distribution of groups concerned

\begin{tabular}{|c|c|c|c|c|c|c|c|}
\hline & \multirow[b]{2}{*}{ Male } & \multirow[b]{2}{*}{ Female } & \multirow[b]{2}{*}{ Total } & \multicolumn{2}{|c|}{ Radiological leaks } & \multicolumn{2}{|c|}{ Clinical leaks } \\
\hline & & & & Male & Female & Male & Female \\
\hline $\begin{array}{l}\text { Left sided hemicolectomy } \\
\text { Mean age (y) }\end{array}$ & 17 & 11 & $\begin{array}{l}28 \\
70 \cdot 3\end{array}$ & 0 & 0 & $\begin{array}{l}0 \\
0\end{array}$ & 0 \\
\hline $\begin{array}{l}\text { Sigmoid colectomy } \\
\text { Mean age }(y)\end{array}$ & 27 & 14 & $\begin{array}{l}41 \\
69 \cdot 2\end{array}$ & 0 & 0 & $\begin{array}{c}1 \\
39 \cdot 0\end{array}$ & 0 \\
\hline $\begin{array}{l}\text { Anterior resection } \\
\text { Mean age }(y)\end{array}$ & 28 & 32 & $\begin{array}{l}60 \\
68 \cdot 1\end{array}$ & $\begin{array}{c}4 \\
73 \cdot 0\end{array}$ & $\begin{array}{l}1 \\
72 \cdot 0\end{array}$ & $\begin{array}{c}2 \\
71 \cdot 0\end{array}$ & $\begin{array}{c}1 \\
75 \cdot 0\end{array}$ \\
\hline $\begin{array}{l}\text { Reversal of Hartmanns } \\
\text { Mean age }(y)\end{array}$ & 8 & 9 & $\begin{array}{l}17 \\
71 \cdot 4\end{array}$ & $\begin{array}{c}1 \\
47 \cdot 0\end{array}$ & 0 & 0 & $\begin{array}{c}1 \\
57 \cdot 0\end{array}$ \\
\hline $\begin{array}{l}\text { Closure of colostomy } \\
\text { Mean age (y) }\end{array}$ & 0 & 1 & $\begin{array}{c}1 \\
70 \cdot 0\end{array}$ & 0 & 0 & 0 & $\begin{array}{l}1 \\
70 \cdot 0\end{array}$ \\
\hline $\begin{array}{l}\text { Total } \\
\text { Mean age (y) }\end{array}$ & $\begin{array}{l}80 \\
67 \cdot 5\end{array}$ & $\begin{array}{l}67 \\
69 \cdot 1\end{array}$ & $\begin{array}{l}147 \\
69 \cdot 2\end{array}$ & $\begin{array}{l}5 \\
67 \cdot 8\end{array}$ & $\begin{array}{l}1 \\
72 \cdot 0\end{array}$ & $\begin{array}{l}3 \\
60 \cdot 3\end{array}$ & $\begin{array}{c}3 \\
67 \cdot 3\end{array}$ \\
\hline Total leaks & & & & & 6 & & 6 \\
\hline
\end{tabular}

sutured. An all-coats technique was used in all the handsewn anastomoses identified in this study.

Dehiscence was noted in eight of $88(9 \cdot 1 \%)$ consultant operations, four of $42(9.5 \%)$ senior registrar operations, and 0 of 17 registrar operations.

\section{Primary pathology (Table III)}

Two thirds (99 of $147,67 \cdot 3 \%$ ) of the surgery was performed for malignant disease, though only half (six of 12, 50\%) of the recorded leaks occurred in this group. Five leaks were seen among the $30(16.7 \%)$ patients operated on for diverticular disease. One of seven $(14.3 \%)$ patients undergoing surgery for sigmoid volvulus developed a leak. As our study was primarily concerned with the effects of microvascular disease on anastomotic leak rates, no distinction was made between elective and emergency surgery, though the disproportionately high leak rate among patients with diverticular disease or sigmoid volvulus may in part be due to the timing of surgery.

\section{Macrovascular disease risk factors and anastomotic leakage}

Figure 1 shows the incidence of MAVD risk factors in those patients with an anastomotic leak compared with those whose anastomosis remained intact.

$\chi^{2}$ Analysis of these data strongly suggests that smoking is associated with an increased incidence of anastomotic breakdown; nine of 12 patients with an anastomotic leak were smokers $(75 \%)$, compared with only 40 of 135

TABLE III Relations between pathology leading to surgery and incidence of leak

\begin{tabular}{llll}
\hline & $\begin{array}{l}\text { Incidence } \\
\text { Number } \\
\text { (\% of total cases) }\end{array}$ & $\begin{array}{l}\text { Radiological leaks } \\
\text { Number } \\
\text { (\% of total leaks) }\end{array}$ & $\begin{array}{l}\text { Clinical leaks } \\
\text { Number } \\
\text { (\% of total leaks) }\end{array}$ \\
\hline Carcinomasis & $18(12 \cdot 2)$ & $1(8 \cdot 3)$ & $0(0)$ \\
Dukes's A & $48(32 \cdot 6)$ & $3(25 \cdot 0)$ & $2(16 \cdot 7)$ \\
Dukes's B & $33(22 \cdot 4)$ & $0(0)$ & $0(0)$ \\
Dukes's C & $99(67 \cdot 3)$ & $4(33 \cdot 8)$ & $2(16 \cdot 7)$ \\
Total & $30(20 \cdot 4)$ & $2(16 \cdot 7)$ & $3(25 \cdot 0)$ \\
Diverticular disease & $7(4 \cdot 8)$ & $0(-)$ & $1(8 \cdot 3)$ \\
Sigmoid volvulus & $4(2 \cdot 7)$ & $0(-)$ & $0(-)$ \\
Benign adenoma & $2(1 \cdot 4)$ & $0(-)$ & $0(-)$ \\
Mesodermal tumours & $2(1 \cdot 4)$ & $0(-)$ & $0(-)$ \\
Urogenital malignancy & $1(0 \cdot 7)$ & $0(-)$ & $0(-)$ \\
Crohn's disease & $1(0 \cdot 7)$ & $0(-)$ & $0(-)$ \\
Ischaemic colitis & $1(0 \cdot 7)$ & $0(-)$ & $6(50 \cdot 0)$ \\
Iatrogenic perforation & 147 & $6(50 \cdot 0)$ & \\
Total & & & \\
\hline
\end{tabular}

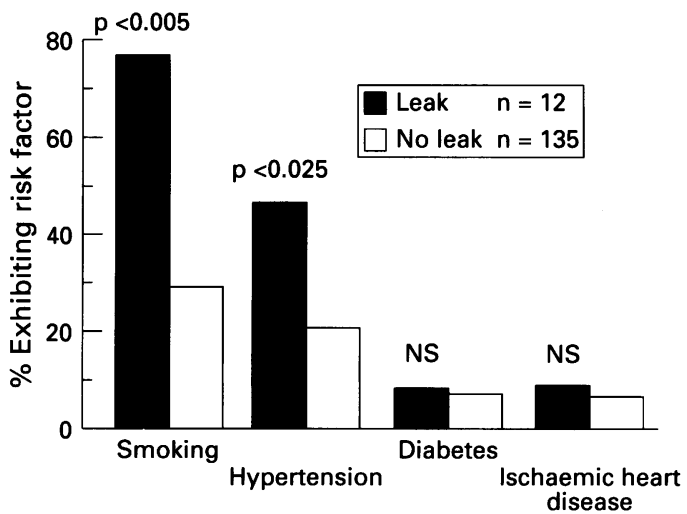

Figure 1: Incidence of macrovascular disease risk factors among patients with leak and no leak ( $\chi^{2}$ test).

patients with intact anastomoses $(29.6 \%)$ $(\mathrm{p}<0.005)$. Six $(50 \%)$ of those who developed anastomotic dehiscence were hypertensive, compared with only $27(20 \%)$ of those who did not, which again was statistically significant $(p<0.025)$. No significant association was seen between the incidence of dehiscence and a history of diabetes or ischaemic heart disease.

Of the 63 patients in this study who did not exhibit any of the four macrovascular risk factors, none suffered anastomotic breakdown. Nine of 68 patients with one risk factor leaked; two of 15 patients with two risk factors leaked, and the only patient in the study with three risk factors also developed dehiscence (Table IV).

\section{Macrovascular disease risk factors and}

microvascular disease

Figure 2 shows the relation between the incidence of macrovascular disease risk factors and the presence or absence of microvascular disease.

Smoking and hypertension in particular were associated with a significantly increased incidence of small vessel disease $(p<0.005$ and $\mathrm{p}<0.025$ respectively, $\chi^{2}$ test).

No significant correlation between ischaemic heart disease and the presence of small vessel disease was seen. Interestingly the data actually suggest a decreased incidence of small vessel disease in patients with diabetes compared with non-diabetics.

Microvascular disease and anastomotic dehiscence Histopathological assessment showed significant small vessel disease in the serosa and submucosal layers only. The serosa was the commonest site of microvascular disease. Sixty four of 67 patients classified as having small vessel disease had evidence of pathological changes in the vessels of this layer, ranging

TABLE IV Incidence of leakage related to number of macrovascular risk factors expressed

\begin{tabular}{lll}
\hline No of risk factors exhibited & No of patients & No of leaks (\%) \\
\hline 0 & 63 & $0(0)$ \\
1 & 68 & $9(13 \cdot 2)$ \\
2 & 15 & $2(13 \cdot 3)$ \\
3 & 1 & $1(100 \cdot 0)$ \\
\hline
\end{tabular}




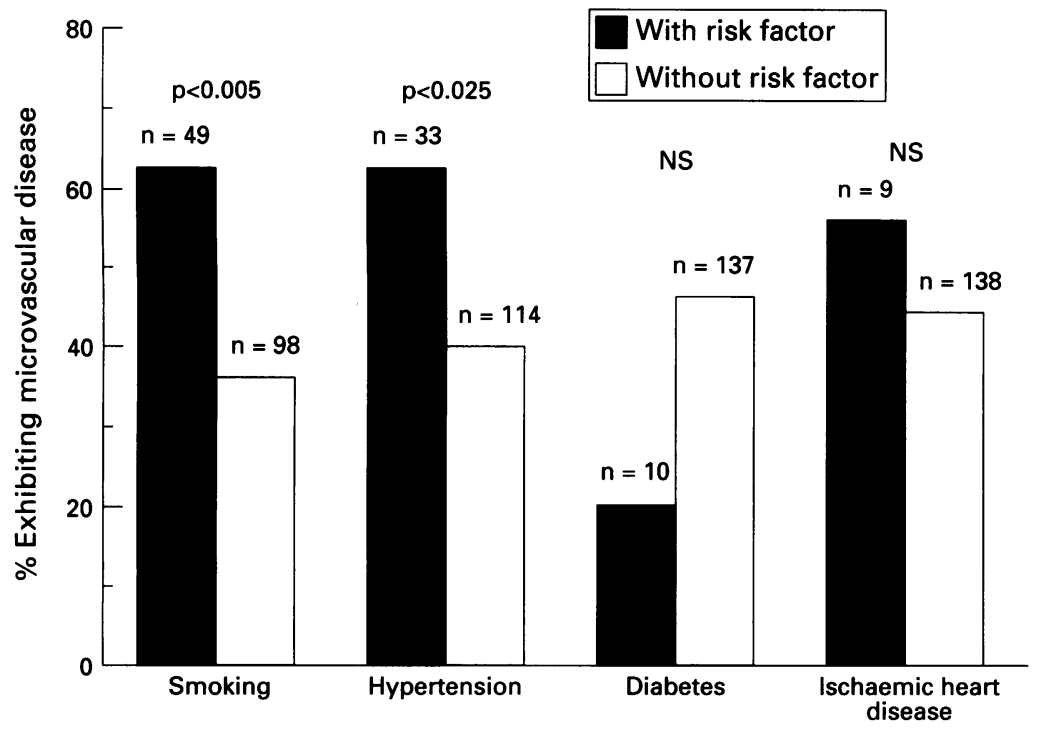

Figure 2: Incidence of microvascular disease in relation to presence of macrovascular disease risk factors ( $\chi^{2}$ test). anterior resection, a factor acknowledged to be of paramount importance, was only recorded in the operation notes in seven of 60 procedures performed. If there were any discrepancy regarding this parameter among the small groups in this study, the results obtained would be less convincing.

This study emphasises the importance of the colonic microcirculation in anastomotic healing. It is interesting to note that microvascular disease was seen most frequently in the serosal layer, though the commonly held belief is that the submucosa is the key tissue layer in anastomotic healing. Whether these data challenge this view is open to debate. As the submucosa derives its blood supply from the serosal plexus, proximal disease may adversely affect submucosal perfusion. The adequacy of submucosal perfusion may still remain the critical factor in predicting anastomotic failure.

A diseased microcirculation will probably lead to poor wound healing as blood flow is reduced, partly because of the physical narrowing of the vessel, and possibly also partly because of the changed responsiveness of the vessel wall to certain vasoactive agents such as serotonin. As it has been shown that plasma serotonin concentrations are raised in smokers, hypertensives, and during surgery, this amine may be playing a crucial part in the development of anastomotic ischaemia.

From our study it has been shown that smokers and hypertensives will probably have small vessel disease. Subsequent studies have also shown that these patients have reduced colonic wall perfusion. ${ }^{16}$ This would lead us to suggest that the surgeon should have a lower threshold for using a proximal diversion in patients who have hypertension or those who smoke. Such a manoeuvre would lessen the mortality and morbidity associated with anastomotic dehiscence should it occur. Furthermore, as a diseased microcirculation is hypersensitive to serotonin, the pharmacological blockade of the smooth muscle mesenteric vessel response to serotonin using a specific serotonin receptor (S2) antagonist may be of value in preserving microcirculatory flow, essential to the anastomotic healing process. A prospective, randomised double blind trial entailing the administration of such an antagonist to patients undergoing colorectal resection and anastomosis is now underway to further explore this hypothesis.

The authors wish to extend their grateful thanks to the staff of the Medical Records Department for their help in locating and retrieving the case notes of all the patients in this study.

1 Fielding LP, Steward-Brown S, Blesovsky L, Kearney G. Anastomotic integrity after operations for large-bowel cancer: a multicentre study. $B M \mathcal{F} 1980 ; 281$ : $411-4$

2 Goligher JC, Graham NG, DeDombal FT. Anastomotic dehiscence after anterior resection of the rectum and sig-

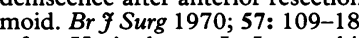

3 Grafner H, Anderson L, Loweenhielm P, Walther B. The healing process of the anastomosed colon. A comparative study using single, double-layer or stapled anastomosis. Dis Colon Rectum 1984; 27: 767-71.

4 Heald RJ, Leicester RJ. The low stapled anastomosis. $\mathrm{Br} \mathcal{J}$ Surg 1981; 68: 333-7.

5 Irvin TT, Goligher JC. Aetiology of disruption of intestinal anastomoses. Br f Surg 1973; 60: 461-4.

6 Koruda MJ, Rolandelli RH. Experimental studies on the healing of colonic anastomoses. $\mathcal{F}$ Surg Res 1990; 48: 504-15.

Figure 3: Incidence of microvascular disease according to tissue layer in patients with anastomotic leak compared with those without. 
7 Schrock TR, Deveney CW, Dunphy JE. Factors contributing to leakage of colonic anastomosis. Ann Surg 1973; ing to leakage

8 Tagart B. Colorectal anastomosis: factors influencing success. F R Soc Med 1981; 74: 111-8.

9 Derrick JR, Pollard HS, Moore RM. The pattern of atherosclerotic narrowing of the celiac and superior mesenteric arteries. Ann Surg 1959; 149: 684-9.

10 Vanhoutte PM. Vascular effects of serotonin and ischaemia. 7 Cardiovasc Pharmacol 1990; 16 (suppl 3): S15-9.

11 Racke K, Schworer H, Simson G. Effects of cigarette smoking or ingestion of nicotine on platelet 5-hydroxytryptaInvestig 1992; 70: 201-4.

12 Gow IF, Corrie JET, Williams BC, Edwards CRW. Development and validation of an improved radioimmunoassay for serotonin in platelet-rich plasma. Clin Chim Acta 1987; 162: $175-88$.

13 Naesh O, Friis JT, Hindberg I, Winther K. Platelet function in surgical stress. Thromb Haemost 1985; 54: 849-52.

14 Lopez JAG, Brown BP, Armstrong ML, Piegors DJ, Heistad DD. Response to the mesenteric circulation in normal and atherosclerotic monkeys: implications for the pathogenesis of non-occlusive intestinal ischaemia. Cardiovasc Res 1989; 23: 117-24.

15 Fawcett A, Vashisht R, Shankar A, Dawson PM, O'Malley $M K$, Nott DM, et al. Microvascular disease and anastomotic dehiscence in the colon. Br $\mathcal{F}$ Surg 1995; 82 : 1483-5. 16 Fawcett A, Shembekar M, Vashisht R, Springall RG, Nott DM. Colonic microvascular disease and anastomotic dehiscence. (Abstract). Br $\mathcal{f}$ Surg 1995; 82: 1556.

\section{IT"EI UTGTV PADIS 90}

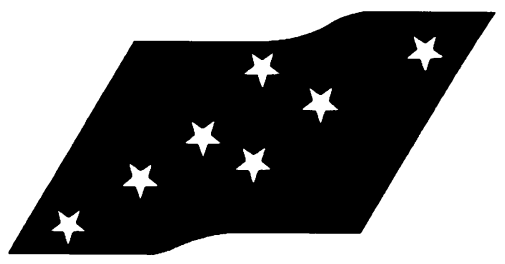

Paris, CNIT convention centre: 2 to 6 November 1996

4 ( $)$ Deadline for submission of abstracts: 1 June 1996 扫 Deadline for advance registration: 1 September 1996

If you have not received the CALL FOR ABSTRACTS \& PRELIMINARY PROGRAMME (including all necessary abstract forms and registration material), please contact:

SOCFI/UEGW 96: 14, rue Mandar, 75002 Paris, France Fax: (33).1.40.26.04.44 